\title{
Comparison of micro push-out bond strengths of two fiber posts luted using simplified adhesive approaches
}

\author{
Emre MUMCU1', Ugur ERDEMIR² and Fulya Toksoy TOPCU³ \\ ${ }^{1}$ Department of Prosthetic Dentistry, Faculty of Dentistry, Istanbul University, Capa, Istanbul 34300, Turkey \\ ${ }^{2}$ Department of Operative Dentistry, Faculty of Dentistry, Istanbul University, Capa, Istanbul 34300, Turkey \\ ${ }^{3}$ Department of Endodontics and Conservative Dentistry, Gulhane Military Medical Academy, Etlik, Ankara 06018, Turkey \\ Corresponding author, Ugur ERDEMIR; E-mail: verdemir@hotmail.com
}

\begin{abstract}
By means of a micro push-out test, this study compared the bond strengths of two types of fiber-reinforced posts cemented with luting cements based on two currently available adhesive approaches as well as evaluated their failure modes. Sixty extracted single-rooted human maxillary central incisor and canine teeth were sectioned below the cementoenamel junction, and the roots were endodontically treated. Following standardized post space preparation, the roots were divided into two fiber post groups and then further into three subgroups of 10 specimens each according to the luting cements. A push-out test was performed to measure regional bond strengths, and the fracture modes were evaluated using a stereomicroscope. At the root section, there were no statistically significant differences $(p>0.05)$ in push-out bond strength among the tested luting cements. Nevertheless, the push-out bond strength values of glass fiberreinforced posts were higher than those of carbon fiber-reinforced posts, irrespective of the adhesive approach used. On failure mode, the predominant failure mode was adhesive failure between dentin and the luting cement.
\end{abstract}

Keywords: Fiber-reinforced post, Luting cement, Push-out test

\section{INTRODUCTION}

Fiber-reinforced composite (FRC) posts, as an alternative to cast posts and cores and metal dowels, were introduced in the early $1990 \mathrm{~s}$ to restore endodontically treated teeth with an excessive loss of tooth structure ${ }^{1,2)}$. The preference for and popularity of FRC posts can be chiefly ascribed to an elastic modulus that is closer to that of dentin ${ }^{3)}$. Other advantages of FRC posts include enabling cementation procedures to be carried out without friction with root canal walls $\mathrm{s}^{1-3)}$ and a reduced risk of vertical root fractures ${ }^{2,4,5)}$. On the latter advantage, several in vitro studies have shown that FRC posts distributed occlusal stresses more evenly in the root dentin, thereby resulting in fewer and more favorable root fractures, which were often reparable ${ }^{6.8)}$.

Where esthetics is of prime importance, quartz or glass fiber posts can be used ${ }^{9}$. With regard to the fiber posts that are currently available on the market, they are composed of unidirectional fibers embedded in a resin matrix in which reinforcing quartz or glass fibers are immersed. Fibers are pre-stressed, and subsequently resin (as a filler) is injected under pressure to fill the spaces between the fibers, giving them solid cohesion ${ }^{10,11)}$.

On the actual bond strength at the post-cementroot interface, it is affected by a slew of factors. Amongst which are the degree of hydration of root canal dentin, surface conditioning agent and luting cement used, cavity configuration factor, the use of eugenol-containing sealers, and the anatomic differences in density and orientation of the dentinal tubules at different levels of the root canal area ${ }^{12-14}$.
Other factors that may pose significant challenges to the bonding procedure, and may hence compromise bond strength, arise from the difficulty of the curing light to reach many parts of apical root canal ${ }^{15)}$, the difficulty of gaining direct vision to the root canal ${ }^{16)}$, and the difficulty of moisture control and adhesive application in the apical region of root canals ${ }^{16)}$. Owing to the small and narrow root canal space especially in the apical region, it has been shown that the bond strength of resin cements to root dentin varied along the root dentin surface, being higher at the cervical region and lower in the apical region ${ }^{13,17,18)}$.

For the bonding of FRC posts to root canal dentin, various luting cements and accompanying adhesive systems have been proposed for this purpose. These materials can be divided into self-etching adhesive and total-etching adhesive systems ${ }^{16)}$. With the recently developed self-adhesive resin cements, no pretreatment of dentin is required. By eliminating the phosphoric acid pretreatment step, the step of rinsing off the phosphoric acid is also eliminated, and hence the need for clinical assessment of optimal dentin wetness after rinsing dentin ${ }^{12}$. In other words, the simpler selfetching adhesive approach requires a reduced number of clinical procedural steps, hence offering the advantages of a shorter adhesive application time and more importantly, reduced technique sensitivity.

As for the bonding performance of self-adhesive resin cements when used to lute fiber posts, it has been assessed in laboratory studies and compared against the performance of total-etching adhesives. However, findings on the performance of self-etching adhesives with regard to fiber post cementation were not consistent. This lack of consensus about the bonding 
performance of self-adhesive cements could be attributed to the limited number of studies carried out on this group of resin cements. To date, the in vitro performance of self-adhesive cements in fiber post cementation has been investigated using the push-out bond strength test ${ }^{17-21)}$, yielding contradicting results whereby a particular self-adhesive cement ran the gamut of being lower than ${ }^{20)}$, comparable to ${ }^{19)}$, or superior to ${ }^{17)}$ the other tested cements in these studies.

On bond strength measurement, a variety of test methods are currently available. Amongst which is the push-out bond strength test, which was first used in 1996 to evaluate bonding to root canal dentin ${ }^{22)}$. It is believed that the push-out test method provides a better estimation of the actual bonding effectiveness than a conventional shear bond strength test. This is because by using a push-out protocol, failure occurs parallel to the post-cement-dentin interface, which resembles the clinical condition ${ }^{22-24)}$. In addition, the push-out test has been considered to be more dependable than the microtensile test for bonded posts because of the high number of premature failures occurring during specimen preparation and the large data distribution associated with microtensile testing ${ }^{25)}$.

In light of the concerns associated with the bonding performance of self-etch, self-adhesive luting cements, the aim of the present study was to compare the pushout bond strength of a self-etch, dual-cure luting cement (Panavia ${ }^{\text {TM }}$ F 2.0, Kuraray, Tokyo, Japan) against those of two dual-cure, self-adhesive luting cements (RelyX ${ }^{\mathrm{TM}}$ Unicem, 3M ESPE, Seefeld, Germany; Maxcem ${ }^{\mathrm{TM}}$, Kerr Corporation, Orange, CA, USA) when used to lute two different FRC posts (Glassix $^{\circledR}$, Harald Nordin sa, Chailly-Montreux, Switzerland; Carbopost ${ }^{\circledR}$, Carbotech, Ganges, France) at three different root regions: cervical, medium, and apical third. The hypotheses tested in the present study were as follows: (1) No measurable differences in bond strength between the post types tested; and (2) No differences in the retention of fiber posts cemented with different luting cements.

\section{MATERIALS AND METHODS}

Sixty single-rooted human maxillary central incisors and canines with fully developed apices extracted for periodontal reasons were selected for use in the present study. The selection criteria were namely: absence of caries or root cracks, and absence of previous endodontic treatments, posts, or crowns. Teeth were hand-scaled and stored in $0.5 \%$ chloramine $\mathrm{T}$ solution at $4^{\circ} \mathrm{C}$ for no more than 6 months until use.

\section{Specimen preparation}

The crown of each tooth was removed $2 \mathrm{~mm}$ above the cementoenamel junction (CEJ), using a low-speed diamond saw (Isomet 1000, Buehler Ltd., Lake Bluff, IL, USA) under copious water cooling. To standardize the root canal length for this study, the roots were cut to a uniform length of $14 \mathrm{~mm}$ and then prepared for endodontic treatment.

Pulp tissue was removed with a barbed broach. The roots were endodontically instrumented to a working length of $1 \mathrm{~mm}$ from the apex using a \#35 Master apical file (Maillefer, Ballaigues, Switzerland). All the root canals were instrumented by the same operator. A step-back technique was used with stainless steel K-files (Union Broach, New York City, NY, USA) and Gates-Glidden drills (sizes 2-4; Union Broach). Throughout the shaping process, irrigation was performed using a $5.25 \%$ sodium hypochlorite solution after each file or drill size change. Following which, the canals were rinsed with distilled water, dried with paper points (Dentsply-Maillefer, Ballaigues, Switzerland), and obturated with gutta-percha cones (Dentsply-Maillefer) and a sealer (AH-Plus ${ }^{\circledR}$; Dentsply DeTrey GmbH, Konstanz, Germany) using a lateral condensation technique.

After the endodontic treatment was completed, the cervical root canal openings were filled with a provisional restorative material (Cavit ${ }^{\mathrm{TM}} \mathrm{G}$, 3M ESPE AG, Seefeld, Germany), and the teeth were stored in $100 \%$ humidity in black film containers for 7 days at $37^{\circ} \mathrm{C}$.

\section{Post luting procedures according to adhesive} approaches

For post space preparation, excess gutta-percha was removed with a warm plugger (Sybron Dental Specialties, Romulus, MI, USA), leaving a minimum apical seal of $4-5 \mathrm{~mm}$ of gutta-percha in the canal space. After post space preparation, post holes were prepared to a depth of $9 \mathrm{~mm}$ from the CEJ. The roots were instrumented using the appropriate drill sizes provided in the kit from the respective post manufacturers. A final flushing of the canal space was accomplished using sterile water, and the canals were dried with paper points (Dentsply-Maillefer). The presence of any residual gutta-percha in the root canal walls along the post space was checked by radiographic evaluation.

The prepared roots were randomly divided into two fiber post groups. Within each fiber post group, the roots were further divided into three subgroups of 10 specimens each according to the luting cements investigated. For the fiber posts used in this study, they were namely: a cylindrical glass fiber post (Glassix, Harald Nordin sa, Chailly-Montreux, Switzerland) of $1.35 \mathrm{~mm}$ diameter and a carbon fiber post (Carbopost ${ }^{\mathbb{B}}$, Carbotech, Ganges, France) of 1.40 $\mathrm{mm}$ diameter. Details of the materials used in this study are given in Table 1.

All posts were marked at a distance of $9 \mathrm{~mm}$ from the apical end -corresponding to the length of the prepared post space, and sectioned horizontally with a water-cooled diamond fissure rotary cutting instrument (Komet-Brasseler GmbH, Lemgo, Germany). After shortening, the post surfaces were cleaned with alcohol, thoroughly rinsed with distilled water, and air-dried. The materials were handled in strict adherence to the 
Table 1 Compositions and application modes of the materials used in the present study

\begin{tabular}{|c|c|c|c|}
\hline $\begin{array}{l}\text { Material and } \\
\text { manufacturer }\end{array}$ & Bonding system & Composition & Application procedures \\
\hline
\end{tabular}

\section{Luting Cement}

Panavia $^{\mathrm{TM}}$ F 2.0

Kuraray Medical Inc.,

Osaka, Japan
ED Primer II

Base: Hydrophobic aromatic and aliphatic dimethacrylate, sodium aromatic sulphinate, $N, N$-diethanol- $p$ toluidine, sodium fluoride, silanized barium glass sodium benzene sulfinate
Mix equal amounts of ED primer liquids $\mathrm{A}$ and $\mathrm{B}$, apply mixture to the post space with a microbrush for $30 \mathrm{~s}$, gently air-dry and then remove excess with paper points. Mix Panavia F 2.0 pastes A and B for $20 \mathrm{~s}$, apply the mixed paste to the post and seat it in place, lightcure for $40 \mathrm{~s}$.

Catalyst: MDPa hydrophobic aromatic and aliphatic dimethacrylate, photoinitiator, dibenzoyl peroxide, hydrophilic dimethacrylate, silanized silica

ED Primer II: $\mathrm{HEMA}^{\mathrm{b}}$, MDP ${ }^{\mathrm{a}}$, 5-NMSA ${ }^{\mathrm{h}}$, dimethacrylate, sodium benzene sulfinate, water, accelerator

\section{RelyX ${ }^{\mathrm{TM}}$ Unicem 3M ESPE, St. Paul, MN, USA}

Powder: Glass fillers, silica, calcium hydroxide, substituted pyrimidine, peroxy compound, pigments, self-cure initiators

\begin{abstract}
Clean and dry canal with paper points and a gentle blow of air, activate and mix the RelyX $\mathrm{X}^{\mathrm{TM}}$ Unicem cement dispensed from capsule for 10-15 s. Apply cement onto the post surface, insert the post and let the cement cure without any interference, followed by light-curing for $40 \mathrm{~s}$.
\end{abstract}

Liquid: Methacrylated phosphoric esters, dimethacrylates, acetate, stabilizers, selfcure initiators, light-cure initiators

Maxcem $^{\mathrm{TM}}$
Kerr Corporation,
Orange, CA, USA
Base paste: $\mathrm{UDMA}^{\mathrm{e}}, \mathrm{CQ}^{\mathrm{d}}$, fluoroaluminosilicate, others
Apply the automixed paste with the aid of a root canal tip and seat the post into the root canal. Remove excess and light-cure for $40 \mathrm{~s}$.

Catalyst paste: Bis-GMAㅁ, TEGDMA ${ }^{\mathrm{f}}$, $\mathrm{GPDM}^{\mathrm{c}}$, barium aluminopolosilicate glass, others

Fiber-reinforced post

Glassix $^{\circledR}$

Harald Nordin sa,

Chailly-Montreux,

Switzerland

Carbopost $^{\circledR}$

Carbotech, Ganges,

France
Glass fiber-reinforced post (glass fiberbraided plait)

${ }^{a}$ MDP: 10-methacryloyloxydecyl dihydrogen phosphate; ${ }^{b}$ HEMA: 2-hydroxyethyl methacrylate; ${ }^{\circ}$ GPDM: glycerol phosphate

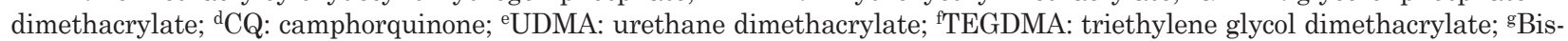
GMA: bisphenol A-glycidyl methacrylate; and h ${ }^{5}$-NMSA: $N$-methacryloyl 5-aminosalicylic acid 
instructions of their respective manufacturers. Before post cementation, no pre-treatment was applied to the post surfaces.

1. Self-etching group

The self-etch luting cement used in this study was Panavia $^{\mathrm{TM}}$ F 2.0 (Kuraray, Tokyo, Japan). For post cementation using Panavia ${ }^{\mathrm{TM}}$ F 2.0 , both the glass fiber post $\left(\right.$ Glassix $\left.^{\circledR}\right)$ and carbon fiber post $\left(\right.$ Carbopost $\left.^{\circledR}\right)$ were cleaned with alcohol and air-dried.

ED Primer II was mixed at a ratio of 1:1, applied to the dentin walls of the post spaces using a microbrush (Microbrush ${ }^{\circledR}$ X, Microbrush Corp., Grafton, WI, USA) for 30 seconds, gently air-dried, and then the excess was removed using paper points. Panavia ${ }^{\mathrm{TM}} \mathrm{F}$ 2.0 pastes $\mathrm{A}$ and $\mathrm{B}$ were mixed for 20 seconds and applied to the posts. After application, the posts were seated into the root canals immediately and excess luting cement was removed using a small brush. Light curing was performed through the posts for 40 seconds using a conventional light curing unit $\left(600 \mathrm{~mW} / \mathrm{cm}^{2}\right.$ output; Hilux Ultra Plus, Benlioglu Dental Inc., Ankara, Turkey). Prior to each luting procedure, light output was monitored using a radiometer (Hilux Curing Light Meter, Benlioglu Dental Inc.) to ensure accurate light intensity.

2. Self-adhesive groups

For the self-adhesive luting cements, the materials used in this study were RelyX $\mathrm{X}^{\mathrm{TM}}$ Unicem (3M ESPE) and Maxcem ${ }^{\mathrm{TM}}$ (Kerr Corporation). Prior to luting with these cements, both the glass fiber post $\left(\right.$ Glassix $\left.^{\circledR}\right)$ and carbon fiber post $\left(\right.$ Carbopost $\left.^{\mathbb{B}}\right)$ were cleaned with alcohol and air-dried.

With RelyX ${ }^{\text {TM }}$ Unicem (3M ESPE), the cement was mixed after dispensing from the capsule and applied directly to the post space through a disposable application tip that was attached to the capsule. After application, the posts were seated immediately. Excess luting cement was removed using a small brush, and the cement was allowed to auto-cure for 5 minutes. Light curing was performed through the posts as described above in the self-etching group.

Maxcem $^{\mathrm{TM}}$ (Kerr Corporation) was an automix, dual-cure resin cement. Thus, it was directly applied to the post space with the aid of a disposable application tip. The posts were seated immediately, excess luting cement was removed using a small brush, and light curing was performed through the posts as described above.

After post cementation using the respective luting procedures, the coronary part of the exposed dentin was completely covered with a glass ionomer cement (Fuji IX ${ }^{\mathrm{TM}}$, GC Corp., Tokyo, Japan). The teeth were then stored in distilled water for 7 days at $37^{\circ} \mathrm{C}$ before testing.

\section{Push-out bond strength evaluation}

To evaluate the bond strength between the fiber posts and the luting cements, a thin-slice push-out test was used in this study ${ }^{25}$. The specimens were sectioned horizontally with a low-speed diamond blade (Isomet

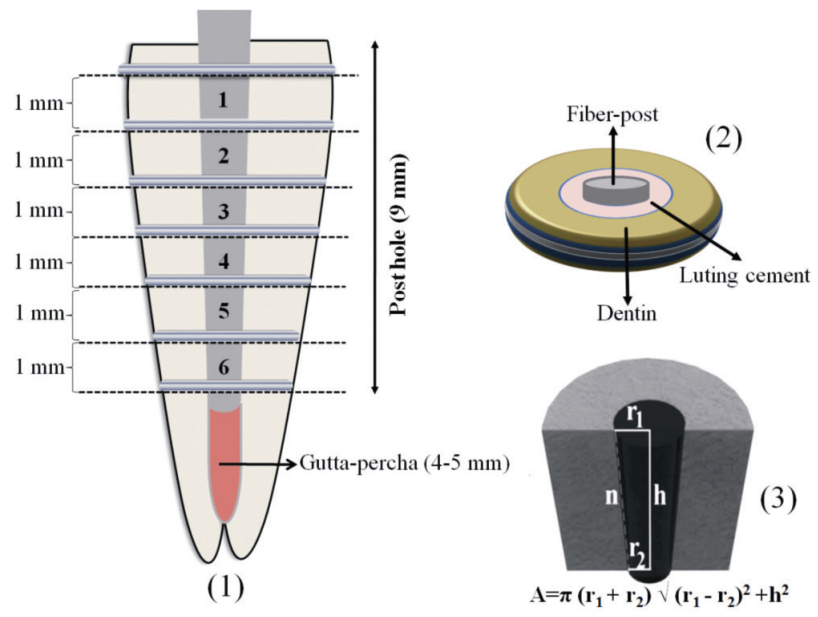

Fig. 1 Schematic view of specimen preparation for pushout strength test. (1) Specimen sectioning into six 1-mm-thick post-dentin sections (cervical, medium, and apical); (2) Slices obtained after sectioning; and (3) Area of post-dentin interface as determined using the formula of the surface area of a frustum: radii of top and bottom surfaces of the post along with the height of the slice $(\mathrm{h}=1$ $\mathrm{mm})$.

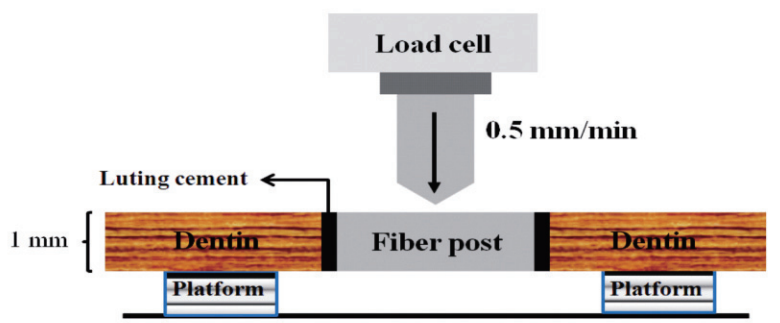

Fig. 2 Push-out test device.

1000, Buehler Ltd.) under water cooling to produce six 1-mm-thick post-dentin sections (cervical, medium, and apical; Fig. 1). The first two slices represented the cervical region (sections 1 and 2), the next two the middle region (sections 3 and 4 ), and the last two (sections 5 and 6 ) the apical region of the prepared post space. None of the slices failed during sectioning, and all slices were used for push-out bond strength evaluation. Each specimen was marked on its coronal surface with an indelible marker, and the exact thickness of each slice was measured using a digital caliper (0.01 mm accuracy; Mitutoyo, Tokyo, Japan).

Each section was attached to a push-out jig (Fig. 2) with a cyanoacrylate adhesive $\left(Z^{2}\right.$ apit ${ }^{\circledR}$, Dental Ventures of America Inc., Corona, CA, USA), whereby the coronal surface faced the jig and the post was centered over the hole of the jig. The post segment was loaded with a cylindrical plunger (1 $\mathrm{mm}$ in diameter), which was centered on the post segment and which had no contact 
with the surrounding dentin surface. Load was applied with a universal testing machine (Shimadzu AG-1, Shimadzu Corp., Tokyo, Japan), in an apical-to-cervical direction with respect to the individual test specimens, at a crosshead speed of $0.5 \mathrm{~mm} / \mathrm{min}$ until the post was dislodged. Push-out bond strength was calculated for each specimen by using the following formula:

$$
\text { Debond stress }=\frac{\text { Debonding force }(N)}{A}
$$

where $A$ =area of the post-dentin surface. The latter was determined using the formula for the surface area of a frustum (radii of the top and bottom surfaces of the post along with the height of the slice $)^{23)}$ as follows: $A=\pi\left(\mathrm{r}_{1}+\mathrm{r}_{2}\right) \sqrt{ }\left\{\left(\mathrm{r}_{1}-\mathrm{r}_{2}\right)^{2}+\mathrm{h}^{2}\right\}$ (Fig. 1). Debond stress values were converted to megapascals (MPa).

\section{Microscopic evaluation}

After push-out bond strength evaluation, the failure mode of each debonded specimen was analyzed by two independent operators using a stereomicroscope (Olympus SZ61, Olympus Optical Co., Tokyo, Japan) at $\times 40$ magnification. The failure modes were classified according to the following criteria: (1) Adhesive failure between dentin and luting cement; (2) Adhesive failure between luting cement and post; (3) Cohesive failure within luting cement; (4) Cohesive failure within the post; and (5) Mixed failure.

One representative specimen of each failure mode was processed for scanning electron microscopy (SEM) evaluation so as to obtain the SEM images of each failure pattern. The slices were rinsed in a 95\% alcohol solution for 1 minute and air-dried. Each slice was mounted on a metallic stub and sputter-coated with $200 \AA$ of gold-palladium in a Polaron SC7620 "Mini" Sputter Coater (Quorum Technologies Ltd., East Sussex, UK) for 5 minutes at a current of $10 \mathrm{~mA}$. Then, each specimen was examined by SEM (JSM 6360LV, Jeol Ltd., Tokyo, Japan) at a $15-\mathrm{kV}$ accelerating voltage under different magnifications $(\times 20$ and $\times 25)$, and photographs were taken.

To observe resin tag formation, one specimen from the cervical section of each luting cement group was prepared for SEM analysis. These cervical section specimens were polished with 600-, 800-, and 1000-grit silicon carbide abrasive papers (Atlas Zimpara, Istanbul, Turkey). To remove the organic and mineral components of dentin, the surfaces of these specimens were etched with $37 \%$ phosphoric acid (3M ESPE, St. Paul, MN, USA) for 30 seconds, rinsed with distilled water, and subsequently deproteinized by immersion in $2 \% \mathrm{NaOCl}$ solution for 120 seconds. After being extensively rinsed with water, the specimens were gently air-dried and dehydrated with alcohol, sputtercoated with gold-palladium, and examined by SEM (JSM 6360LV, Jeol) at a $15-\mathrm{kV}$ accelerating voltage under different magnifications $(\times 900, \times 1000$, and $\times 1200$ ), and photographs were taken.

\section{Statistical analysis}

Push-out bond strength data were first verified using the Shapiro-Wilk test for normality of data distribution and by Levene's test for homogeneity of variances. A multivariate analysis of variance (MANOVA) at a $95 \%$ level of confidence was subsequently performed on the push-out bond strength data with the three levels of root region (cervical, medium, and apical) as the dependent variables, and luting cement and fiber post type as fixed factors. Post hoc tests were carried out using Bonferroni's multiple comparison test, with a probability level set at $\alpha=0.05$ for statistical significance.

\section{RESULTS}

\section{Push-out bond strength}

Table 2 presents the means and standard deviations of the bond strength values $(\mathrm{MPa})$ achieved upon dislodging the posts from the three root regions in each luting cement group. The box-and-whisker plots of these bond strength values of glass and carbon fiber posts are shown in Figs. 3 and 4 respectively. Multivariate ANOVA revealed that the fiber post type was a significant factor affecting the push-out bond strength in the medium $(F=25.940, p<0.001)$ and apical $(F=57.717, p<0.001)$ root regions, but the interaction between the luting cement and fiber post type was not significant $(p>0.05)$ among the root dentin regions

Table 2 Mean push-out bond strengths values (MPa) achieved upon dislodging the posts from each root region in each group

\begin{tabular}{lcccccc}
\hline & \multicolumn{2}{c}{ Cervical } & \multicolumn{2}{c}{ Medium } & \multicolumn{2}{c}{ Apical } \\
\hline Ganavia & $16.24(2.81)^{\mathrm{A}}$ & $13.96(3.29)^{\mathrm{A}}$ & $8.86(2.53)^{\mathrm{A}}$ & $7.77(1.85)^{\mathrm{A}}$ & $6.77(1.52)^{\mathrm{A}}$ & $3.69(1.19)^{\mathrm{A}}$ \\
RelyX & $14.92(4.32)^{\mathrm{A}}$ & $14.49(3.53)^{\mathrm{A}}$ & $10.62(1.86)^{\mathrm{A}}$ & $7.66(1.41)^{\mathrm{A}}$ & $6.19(1.49)^{\mathrm{A}}$ & $4.22(1.21)^{\mathrm{A}}$ \\
Maxcem & $14.18(3.59)^{\mathrm{A}}$ & $13.14(3.60)^{\mathrm{A}}$ & $10.21(1.77)^{\mathrm{A}}$ & $6.78(1.78)^{\mathrm{A}}$ & $6.26(1.74)^{\mathrm{A}}$ & $3.42(0.57)^{\mathrm{A}}$ \\
\hline
\end{tabular}

All values are presented as mean (SD). The same superscript letters demonstrate no significant differences in each column according to the Bonferroni test at 5\% level. 
(Table 3).

Post hoc analysis showed that irrespective of the luting cement, glass fiber-reinforced posts demonstrated higher bond strength than the carbon fiber-reinforced posts in all the root regions (Table 4). With Panavia ${ }^{\mathrm{TM}}$ F 2.0, the glass fiber-reinforced post showed significantly higher bond strength value $(p<0.001)$ than the carbon fiber-reinforced post in the apical root region. With RelyX ${ }^{\mathrm{TM}}$ Unicem $(p<0.05)$ and Maxcem ${ }^{\mathrm{TM}}$ $(p<0.001)$, the glass fiber-reinforced post showed significantly higher bond strength values than the

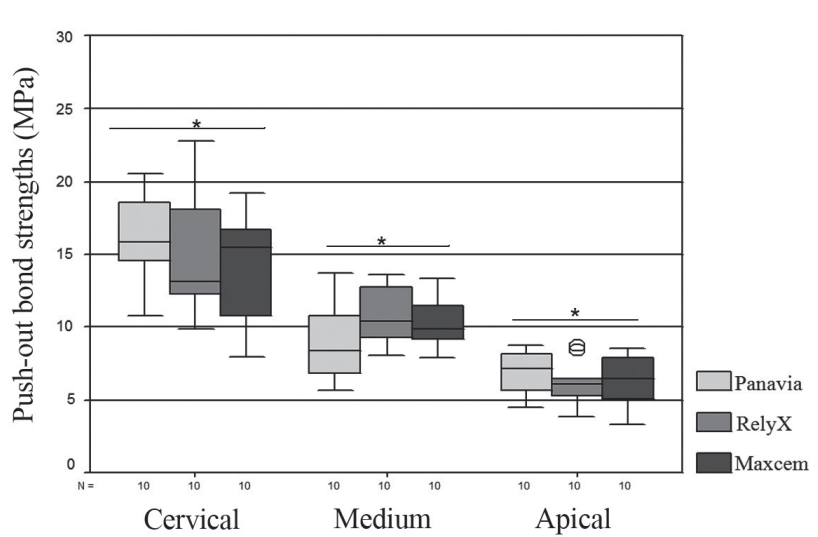

Fig. 3 Box-and-whisker plots, including medians and quartiles, indicating the bond strength values of the tested luting cements for glass fiber post with respect to the three root segment sites (cervical, medium, apical). Circles indicate outliners. Horizontal lines connecting groups indicate which groups do not differ statistically at $p=0.05$. carbon fiber-reinforced post in the medium and apical root regions. For both fiber post types, the apical region resulted in statistically lower bond strengths than the cervical region $(p<0.05$; Table 2$)$.

Irrespective of the type of fiber-reinforced post, the highest bond strength was recorded for Panavia ${ }^{\mathrm{TM}}$ F 2.0 $(16.24 \pm 2.81)$ in the cervical root region, which was not significantly different from RelyX ${ }^{\mathrm{TM}}$ Unicem (14.92 $\pm 4.32, p=1.000)$ and Maxcem $^{\mathrm{TM}} \quad(14.18 \pm 3.59$, $p=0.649)$. In the medium and apical root regions, no statistically significant differences $(p>0.05)$ were

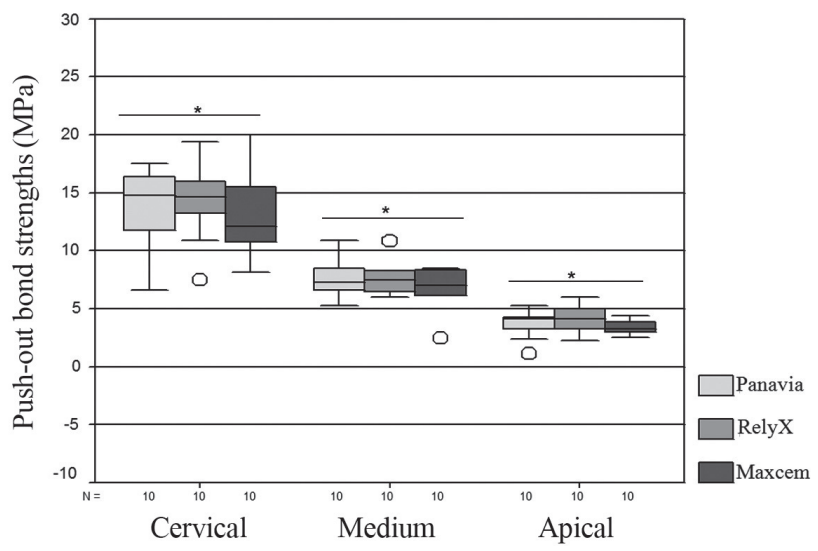

Fig. 4 Box-and-whisker plots, including medians and quartiles, indicating the bond strength values of the tested luting cements for carbon fiber post with respect to the three root segment sites (cervical, medium, apical). Circles indicate outliners. Horizontal lines connecting groups indicate which groups do not differ statistically at $p=0.05$

Table 3 Multivariate ANOVA comparison of luting cements and fiber post types

\begin{tabular}{|c|c|c|c|c|c|c|}
\hline Source & $\begin{array}{c}\text { Dependent } \\
\text { variable }\end{array}$ & $\begin{array}{c}\text { Type III sum of } \\
\text { squares }\end{array}$ & $d f$ & Mean square & $F$ & $p$ \\
\hline \multirow{3}{*}{ Corrected Model } & Cervical & 12648.993(a) & 6 & 2108.166 & 167.071 & $<0.001$ \\
\hline & Medium & 4603.671(b) & 6 & 767.278 & 213.377 & $<0.001$ \\
\hline & Apical & $1663.098(\mathrm{c})$ & 6 & 277.183 & 154.585 & $<0.001$ \\
\hline \multirow{3}{*}{ Fiber post type } & Cervical & 23.438 & 1 & 23.438 & 1.857 & 0.179 \\
\hline & Medium & 93.276 & 1 & 93.276 & 25.940 & $<0.001$ \\
\hline & Apical & 103.491 & 1 & 103.491 & 57.717 & $<0.001$ \\
\hline \multirow{3}{*}{ Luting cement } & Cervical & 21.967 & 2 & 10.983 & 0.870 & 0.425 \\
\hline & Medium & 7.546 & 2 & 3.773 & 1.049 & 0.357 \\
\hline & Apical & 1.921 & 2 & 0.960 & 0.536 & 0.588 \\
\hline \multirow{3}{*}{$\begin{array}{l}\text { Fiber post type * } \\
\text { Luting cement }\end{array}$} & Cervical & 8.881 & 2 & 4.440 & 0.352 & 0.705 \\
\hline & Medium & 15.402 & 2 & 7.701 & 2.142 & 0.127 \\
\hline & Apical & 3.404 & 2 & 1.702 & 0.949 & 0.393 \\
\hline
\end{tabular}

a: $R^{2}=0.949$ (Adjusted $R^{2}=0.943$ ); b: $R^{2}=0.960$ (Adjusted $R^{2}=0.955$ ); and $c: R^{2}=0.945$ (Adjusted $R^{2}=0.939$ ).

Dependent Variables: Cervical, medium, and apical

Fixed Factors: Fiber post type and luting cement

$d f$ : degrees of freedom 
observed among Panavia ${ }^{\mathrm{TM}}$ F 2.0, RelyX ${ }^{\mathrm{TM}}$ Unicem, and Maxcem $^{\mathrm{TM}}$.

\section{Failure mode analysis}

Table 5 shows the distribution of failure modes in this study. In most of the experimental groups, adhesive failure between dentin and luting cement was the most frequently occurring failure mode ( $n=67$ for glass fiber posts and $n=80$ for carbon fiber posts; Fig. 5a), followed by adhesive failure between post and luting cement

Table 4 Comparison of post types according to the luting cements for each root region

Glass fiber/Carbon fiber

$p$

\begin{tabular}{lc}
\hline Panavia $^{\mathrm{TM}} \mathrm{F} 2.0$ & \\
Cervical & 0.113 \\
Medium & 0.287 \\
Apical & $<0.001$ \\
RelyX ${ }^{\mathrm{TM}}$ Unicem & 0.810 \\
Cervical & 0.001 \\
Medium & 0.004 \\
Apical & \\
Maxcem & \\
Cervical & 0.527 \\
Medium & $<0.001$ \\
Apical & $<0.001$ \\
\hline
\end{tabular}

Bonferroni post hoc comparison results after multivariate ANOVA
( $n=66$ for glass fiber posts and $n=47$ for carbon fiber posts; Fig. 5b). Other failure types were determined as mixed failures ( $n=27$ for glass fiber posts and $n=24$ for carbon fiber posts; Fig. 5c) and cohesive failure of luting cement ( $n=18$ for glass fiber posts and $n=23$ for carbon fiber posts; Fig. 5d). No cohesive failures within the post were observed in this study. Two samples from the glass fiber post group and six samples from the carbon fiber post group could not be evaluated microscopically because of the loss of samples during the push-out test procedure.

\section{Interfacial morphology observation}

Figure 6 shows the interfacial micromorphologies of the bonded specimens at the cervical region based on SEM analysis. Dentin pre-treatment with ED Primer II of Panavia $^{\mathrm{TM}}$ F 2.0 resulted in dentin demineralization with different depths of resin penetration (Fig. 6a). However, no resin tag formation was observed in the tested self-adhesive cements (Figs. 6b and 6c).

\section{DISCUSSION}

In the present study, the push-out bond strengths of two different post types with three different luting cements at three different root regions after dual polymerization were measured. In light of the pushout test results, the first hypothesis of this study (i.e., no measurable difference in bond strength between the post types tested) was rejected. In particular, the statistical significant difference in bond strength results between glass fiber- and carbon fiber-reinforced composite posts suggested that the amount of light transmitted by the glass fiber-reinforced post permitted curing of the luting cement throughout the apical region of the tooth. Consequently, significantly higher push-out bond strength was achieved with the glass fiber-reinforced post in the medium and apical root regions than the carbon fiber-reinforced post. The

Table 5 Distribution of failure modes according to the experimental groups (\%)

\begin{tabular}{|c|c|c|c|c|c|c|c|}
\hline \multirow[b]{2}{*}{$\begin{array}{l}\text { Experimental } \\
\text { groups }\end{array}$} & \multicolumn{7}{|c|}{ Failure modes } \\
\hline & & 1 & 2 & 3 & 4 & 5 & $\begin{array}{c}\text { Samples cannot } \\
\text { be evaluated }\end{array}$ \\
\hline \multirow{4}{*}{$\begin{array}{l}\text { Glass fiber- } \\
\text { reinforced post } \\
\left(\text { Glassix }^{\circledR}\right)\end{array}$} & Panavia $^{\mathrm{TM}}$ F 2.0 & $28(47)$ & $20(33)$ & $3(5)$ & - & $9(15)$ & - \\
\hline & RelyX'TM Unicem & $20(33)$ & $25(42)$ & $2(3)$ & - & $12(20)$ & $1(2)$ \\
\hline & Maxcem $^{\mathrm{TM}}$ & $19(45)$ & $21(35)$ & $13(22)$ & - & $6(10)$ & $1(2)$ \\
\hline & Total & $67(37)$ & $66(37)$ & $18(10)$ & - & $27(15)$ & $2(1)$ \\
\hline \multirow{4}{*}{$\begin{array}{l}\text { Carbon fiber- } \\
\text { reinforced post } \\
\left(\text { Carbopost }^{\circledR}\right)\end{array}$} & Panavia $^{\mathrm{TM}} \mathrm{F} 2.0$ & $29(48)$ & $18(30)$ & $5(8)$ & - & $7(12)$ & $1(2)$ \\
\hline & RelyX'TM Unicem & $27(45)$ & $15(25)$ & $6(10)$ & - & $10(17)$ & $2(3)$ \\
\hline & Maxcem $^{\mathrm{TM}}$ & $24(40)$ & $14(23)$ & $12(20)$ & - & $7(12)$ & $3(5)$ \\
\hline & Total & $80(44)$ & $47(26)$ & $23(13)$ & - & $24(13)$ & $6(4)$ \\
\hline
\end{tabular}

1: Adhesive failure between dentin and luting cement; 2: Adhesive failure between luting cement and fiber post;

3: Cohesive failure within the luting cement; 4: Cohesive failure within the post; and 5: Mixed failure 


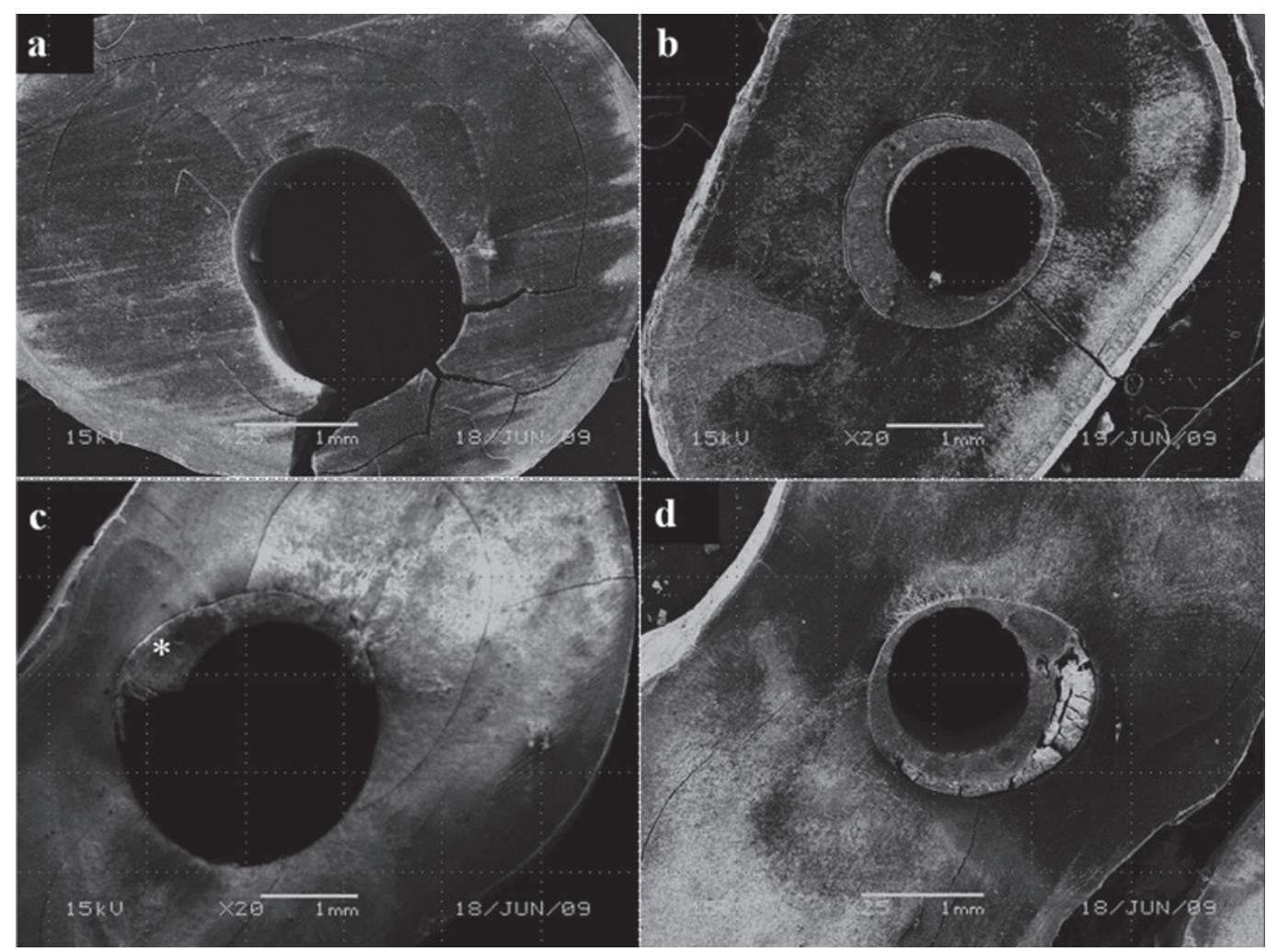

Fig. 5 Scanning electron microscopy (SEM) photographs of failed specimens: (a) Specimen which failed adhesively between root dentin and luting cement; (b) Specimen which failed adhesively between post and cement; (c) Specimen representative of mixed failure, where * indicates visible remnants of luting cement; and (d) Specimen which failed cohesively within the luting cement (original magnification $\times 25$; bar: $1 \mathrm{~mm}$ ).

result of this study echoed the finding by Boschian et $a l .{ }^{26)}$, in that the push-out test employed in their study also revealed that the combination of translucent posts and light-polymerized resin cements resulted in the highest bond strength values.

On the effect of root region on push-out bond strength, the results of this study also echoed those of previous studies ${ }^{13,24,27)}$ in that root region was found to significantly affect push-out bond strength. Irrespective of post type, highest bond strength values were achieved in the cervical region, whereas the lowest values were obtained in the apical region ${ }^{13,24,27)}$. This outcome was to be expected on two fronts: more difficult access to the apical region and a possible limitation of cement flow. At the medium and apical regions, reduction in curing light transmission could account for a decrease in the polymerization of the luting cements in these regions, thereby accounting for the lower bond strengths achieved by the luting cements in these regions. As for the vast difference in push-out bond strength between the cervical and apical root regions, it could be attributed to the easy accessibility of the cervical region versus that of the apical region, hence making it easier for a more thorough etching process and application of adhesive agents. On the other hand, some authors ${ }^{18,28)}$ obtained the best results in the apical region. Such discrepancies in bond strength results could be attributed to differences in the distribution and density of dentinal tubules at different root regions. It has been reported that the density of dentinal tubules in the cervical region was higher than that in the apical region, and that the diameter of tubules decreased in the apical direction ${ }^{29}$.

Another factor at play that may cause reduced dentin bond strengths is the polymerization shrinkage stress created by the luting cement within the long narrow post space. These shrinkage stresses are caused by a high C-factor (ratio of bonded to nonbonded surfaces) of the post space, which may even exceed 200 ${ }^{13}$. With resin composite restorations, the Cfactor is much higher and more complex in root canals than in cavity preparations ${ }^{30)}$. To overcome reductions in dentin bond strength caused by rapid polymerization shrinkage - especially that of thin layers of light-cure resin composite cements, dual-cure luting cements which contain a chemically activated component have since emerged on the market ${ }^{13,31}$.

For luting cements, their behavior is influenced by 

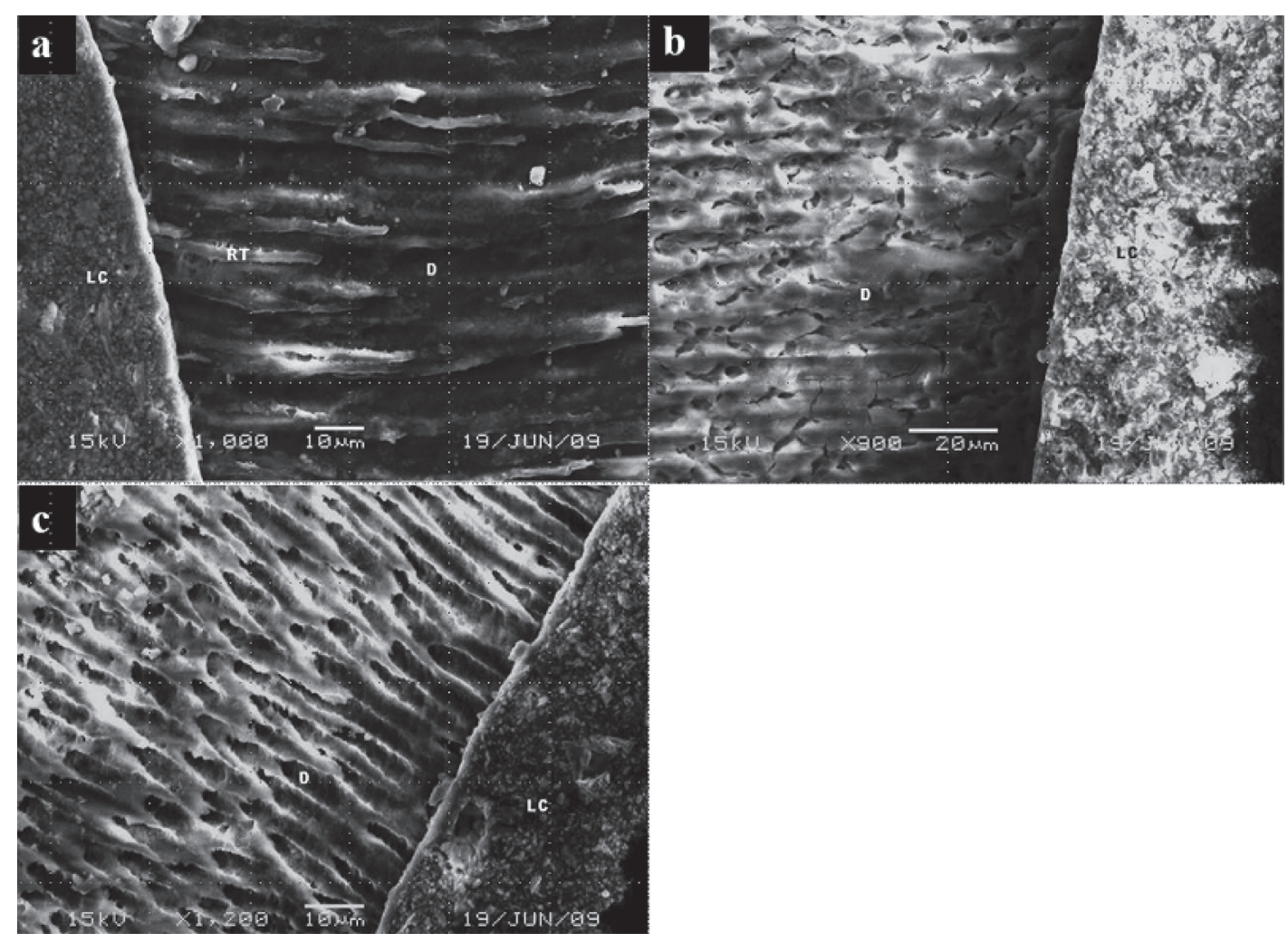

Fig. 6 Scanning electron microscopy (SEM) photographs of interfacial micromorphologies of the bonded specimens: (a) Representative SEM photomicrograph of interface between dentin and Panavia $^{\mathrm{TM}}$ F 2.0 luting cement in cervical root region (original magnification $\times 1000$; bar: 10 $\mu \mathrm{m})$. LC: Luting cement, RT: resin tag, D: dentin; (b) Representative SEM photomicrograph of interface between dentin and RelyX ${ }^{\mathrm{TM}}$ Unicem luting cement in cervical root region (original magnification $\times 900$; bar: $10 \mu \mathrm{m}$ ). LC: Luting cement, D: dentin; and (c) Representative SEM photomicrograph of interface between dentin and Maxcem ${ }^{\mathrm{TM}}$ luting cement in cervical root region (original magnification $\times 1200$; bar: $10 \mu \mathrm{m}$ ). LC: Luting cement, D: dentin.

several factors: the adhesive approach (pre-etched or self-adhesive), the type of initiation ${ }^{32}$, and the compatibility between adhesive and cement. The adhesive system bonds to root canal dentin by diffusion of the hydrophilic bonding agent into the collagenous layer - a phenomenon that depends on whether the smear layer is present or eliminated. It has been reported that thick smear layers and other debris retained on root canal walls after acid-etching ${ }^{33)}$ might prevent optimal adhesive infiltration and that selfetching primers might not be able to etch through thick smear layers ${ }^{34)}$. In the present study, no significant differences in bond strength were found between the self-etch group and the self-adhesive groups. Therefore, the second hypothesis of this study (i.e., no differences in the retention of fiber posts cemented with different luting cements) was accepted. Results of this study echoed those of previous studies ${ }^{19,35)}$ in that there were no statistically significant differences between the bonding performance of self-etch resin luting cements and that of self-adhesive resin luting cements. Goracci et $a l .{ }^{19)}$ showed that the push-out bond strength of self- adhesive cement (RelyX $\mathrm{X}^{\mathrm{TM}}$ Unicem) was comparable to that of self-etching resin-based cement (Panavia $^{\mathrm{TM}} \mathrm{F}$ 2.0). Further, De Munck et al. ${ }^{35)}$ also showed that there were no statistically significant differences in microtensile bond strength ( $\mu$ TBS) to enamel and dentin between RelyX ${ }^{\mathrm{TM}}$ Unicem and Panavia ${ }^{\mathrm{TM}}$ F 2.0. On the other hand, it should be mentioned that there were studies ${ }^{18,36)}$ whose findings contradicted this claim.

The adhesive formulation of Panavia ${ }^{\mathrm{TM}}$ F 2.0 contained a phosphate-based functional monomer, 10MDP. This molecule forms chemical bonds with the calcium in hydroxyapatite remaining around the collagen fibrils within the hybrid layer ${ }^{37)}$. The MDPcalcium salt formed has low solubility in water, hence rendering the interfacial bond hydrolytically stable ${ }^{38)}$. Just like the self-etching primer formulations, selfadhesive cements also contain multifunctional phosphoric-acid methacrylates that demineralize and infiltrate the tooth substrate, thereby resulting in micromechanical retention and chemical adhesion to hydroxyapatite ${ }^{39)}$. Moreover for RelyX $\mathrm{X}^{\mathrm{TM}}$ Unicem, it was claimed by the manufacturer to have high tolerance to 
moisture because water was formed during the neutralization reaction of phosphoric-acid methacrylate, basic fillers, and hydroxyapatite ${ }^{18)}$. This could thus well explain the good bonding performance of RelyX $\mathrm{X}^{\mathrm{TM}}$ Unicem against that of Maxcem ${ }^{\mathrm{TM}}$ in the present study.

On the test method used to evaluate fiber post adhesion to root canal walls, the thin-slice push-out test is considered to be the most accurate and reliable technique when compared with conventional and modified microtensile bond strength testing methods. Other advantages of the push-out test method include allowing several specimens to be fabricated out of one root, as well as testing for regional differences in bond strength between root segments ${ }^{25)}$. In light of these superior advantages, the push-out strength test was the preferred testing method for the present study.

Analysis of the failure modes in the present study revealed that most failures occurred between dentin and cement, which was in accordance with the results of a recently published investigation ${ }^{16)}$. For the next most frequently occurring failure mode in this study, it was of an adhesive nature at the cement and post interface. On the latter type of failure, it could be due to an absence of chemical union between the epoxy resin-based posts and the methacrylate-based resins, thus leading to a proposed use of silane to improve bonding mechanism. However, in the present study, no silane pretreatment was performed on the post surface, which could thus explain why adhesive failure between luting cement and fiber post was one of the frequently occurring failure modes. On cohesive failures, most of which occurred within the luting cement in the Maxcem $^{\mathrm{TM}}$ group. This could be attributed to the lower bond strength of this cement.

On resin tag formation, the self-etch luting cement exhibited resin penetration into the dentin and resin tags of different lengths were identified. With the selfadhesive luting cements, there was no evidence of resin penetration into the dentin nor signs of resin tag formation.

\section{CONCLUSIONS}

Within the limitations of the present investigation, the following conclusions were drawn:

1. The push-out bond strength values of glass fiberreinforced post in the medium and apical root regions were significantly higher than those of carbon fiber-reinforced post.

2. For each luting cement, their mean push-out bond strength values at the cervical region were higher than those at the medium and apical regions.

3. In each root region, the self-etch and selfadhesive luting cements demonstrated similar push-out bond strengths for each post type.

\section{ACKNOWLEDGMENTS}

The authors thankfully acknowledge the support of
Gazi University (DPT Project No: 2001K120590), especially with the use of its laboratories and facilities for this study. The authors would also like to thank Dimsan Dental Co. Ltd. and Kuraray, Turkey for supplying the dentin bonding materials needed for this study.

\section{REFERENCES}

1) Duret B, Reynaud M, Duret F. New concept of coronoradicular reconstruction: the Composipost (1). Chir Dent Fr 1990; 60: 131-141.

2) Asmussen E, Peutzfeldt A, Heitmann T. Stiffness, elastic limit, and strength of newer types of endodontic posts. J Dent 1999; 27: 275-278.

3) Torbjörner A, Karlsson S, Odman PA. Survival rate and failure characteristics for two post designs. J Prosthet Dent 1995; 73: 439-444.

4) Trope M, Maltz DO, Tronstad L. Resistance to fracture of restored endodontically treated teeth. Endod Dent Traumatol 1985; 1: 108-111.

5) Sirimai S, Riis DN, Morgano SM. An in vitro study of the fracture resistance and the incidence of vertical root fracture of pulpless teeth restored with six post-and-core systems. J Prosthet Dent 1999; 81: 262-269.

6) Bateman G, Ricketts DN, Saunders WP. Fibre-based post systems: a review. Br Dent J 2003; 195: 43-48.

7) Schwartz RS, Robbins JW. Post placement and restoration of endodontically treated teeth: a literature review. J Endod 2004; 30: 289-301.

8) Fokkinga WA, Kreulen CM, Vallittu PK, Creugers NHJ. A structured analysis of in vitro failure loads and failure modes of fiber, metal and ceramic post-and-core systems. Int J Prosthodont 2004; 17: 476-482.

9) Vichi A, Ferrari M, Davidson CL. Influence of ceramic and cement thickness on the masking of various type of opaque posts. J Prosthet Dent 2000; 83: 412-417.

10) Grandini S, Goracci C, Monticelli F, Tay FR, Ferrari M. Fatigue resistance and structural characteristics of fiber posts: three-point bending test and SEM evaluation. Dent Mater 2005; 21: 75-82.

11) Perdigäo J, Gomes G, Augusto V. The effect of dowel space on the bond strengths of fiber posts. J Prosthodont 2007; 16: 154-164.

12) Van Meerbeek B, De Munck J, Yoshida Y, Inoue S, Vargas M, Vijay P, Van Landuyt K, Lambrechts P, Vanherle G. Buonocore memorial lecture. Adhesion to enamel and dentin: current status and future challenges. Oper Dent 2003; 28: 215-235.

13) Bouillaguet S, Troesch S, Wataha JC, Krejci I, Meyer JM, Pashley DH. Microtensile bond strength between adhesive cements and root canal dentin. Dent Mater 2003; 19: 199205.

14) Vano M, Cury AH, Goracci C, Chieffi N, Gabriele M, Tay FR, Ferrari M. The effect of immediate versus delayed cementation on the retention of different types of fiber post in canals obturated using a eugenol sealer. J Endod 2006; 32: 882-885.

15) Roberts HW, Leonard DL, Vandewalle KS, Cohen ME, Charlton DG. The effect of a translucent post on resin composite depth of cure. Dent Mater 2004; 20: 617-622.

16) Zicari F, Couthino E, De Munck J, Poitevin A, Scotti R, Naert I, Van Meerbeek B. Bonding effectiveness and sealing ability of fiber-post bonding. Dent Mater 2008; 24: 967-977.

17) Huber L, Cattani-Lorente M, Shaw L, Krejci I, Bouillaguet S. Push-out bond strengths of endodontic posts bonded with different resin-based luting cements. Am J Dent 2007; 20: 
$167-172$

18) Bitter K, Meyer-Lueckel H, Priehn K, Kanjuparambil JP, Neumann K, Kielbassa AM. Effects of luting agent and thermocycling on bond strengths to root canal dentine. Int Endod J 2006; 39: 809-818.

19) Goracci C, Sadek FT, Fabianelli A, Tay FR, Ferrari M. Evaluation of the adhesion of fiber posts to intraradicular dentin. Oper Dent 2005; 30: 627-635.

20) De Durâo Mauricio PJ, González-López S, Aguilar-Mendoza JA, Félix S, González-Rodríguez MP. Comparison of regional bond strength in root thirds among fiber-reinforced posts luted with different cements. J Biomed Mater Res B 2007; 83: 364-372.

21) Wang VJ, Chen YM, Yip KH, Smales RJ, Meng QF, Chen L. Effect of two fiber post types and two luting cement systems on regional post retention using the push-out test. Dent Mater 2008; 24: 372-377.

22) Patierno JM, Rueggeberg FA, Anderson RW, Weller RN, Pashley DH. Push-out strength and SEM evaluation of resin composite bonded to internal cervical dentin. Endod Dent Traumatol 1996; 12: 227-236.

23) Drummond JL, Sakaguchi RL, Racean DC, Wozny J, Steinberg AD. Testing mode and surface treatment effects on dentin bonding. J Biomed Mater Res 1996; 32: 533-541.

24) Perdigão J, Geraldeli S, Lee IK. Push-out bond strengths of tooth-colored posts bonded with different adhesive systems. Am J Dent 2004; 17: 422-426.

25) Goracci C, Tavares AU, Fabianelli A, Monticelli F, Raffaelli O, Cardoso PC, Tay F, Ferrari M. The adhesion between fiber posts and root canal walls: comparison between microtensile and push-out bond strength measurements. Eur J Oral Sci 2004; 112: 353-361.

26) Boschian Pest L, Cavalli G, Bertani P, Gagliani M. Adhesive post-endodontic restorations with fiber posts: push-out tests and SEM observations. Dent Mater 2002; 18: 596-602.

27) Bolhuis P, De Gee A, Feilzer A. The influence of fatigue loading on the quality of the cement layer and retention strength of carbon fiber post resin composite core restorations. Oper Dent 2005; 30: 220-227.

28) Muniz L, Mathias P. The influence of sodium hypoclorite and root canal sealers on post retention in different dentin regions. Oper Dent 2005; 30: 533-539.

29) Ferrari M, Mannocci F, Vichi A, Cagidiaco MC, Mjör IA. Bonding to root canal: structural characteristics of the substrate. Am J Dent 2000; 13: 255-260.

30) Tay FR, Loushine RJ, Lambrechts P, Weller RN, Pashley DH. Geometric factors affecting dentin bonding in root canals: a theoretical modeling approach. J Endod 2005; 31: 584-589.

31) Peutzfeldt A. Dual-cure resin cements: in vitro wear and effect of quantity of remaining double bonds, filler volume, and light curing. Acta Odontol Scand 1995; 53: 29-34.

32) Yoldas O, Alacam T. Microhardness of composites in simulated root canals cured with light transmitting posts and glass-fiber reinforced composite posts. J Endod 2005; 31: 104-106.

33) Serafino C, Gallina G, Cumbo E, Ferrari M. Surface debris of canal walls after post space preparation in endodontically treated teeth: a scanning electron microscopic study. Oral Surg Oral Med Oral Pathol Oral Radiol Endod 2004; 97: 381-387.

34) Carvalho RM, Pegoraro TA, Tay FR, Pegoraro LF, Silva NR, Pashley DH. Adhesive permeability affects coupling of resin cements that utilize self-etching primers to dentine. J Dent 2004; 32: 55-65.

35) De Munck J, Vargas M, Van Landuyt K, Hikita K, Lambrechts P, Van Meerbeek B. Bonding of an autoadhesive luting material to enamel and dentin. Dent Mater 2004; 20: 963-971.

36) Radovic I, Mazzitelli C, Chieffi N, Ferrari M. Evaluation of the adhesion of fiber posts cemented using different adhesive approaches. Eur J Oral Sci 2008; 116: 557-563.

37) Fukegawa D, Hayakawa S, Yoshida Y, Suzuki K, Osaka A, Van Meerbeek B. Chemical interaction of phosphoric acid ester with hydroxyapatite. J Dent Res 2006; 85: 941-944.

38) Yoshida Y, Nagakane K, Fukuda R, Nakayama Y, Okazaki M, Shintani H, Inoue S, Tagawa Y, Suzuki K, De Munck J, Van Meerbeek B. Comparative study on adhesive performance of functional monomers. J Dent Res 2004; 83: 454-458.

39) Radovic I, Monticelli F, Goracci C, Vulicevic ZR, Ferrari M. Self-adhesive resin cements: a literature review. J Adhes Dent 2008; 10: 251-258. 